\title{
Kinetic modelling of pyrolysis of cellulose using CPD model: effect of salt
}

\author{
Samreen Hameed ${ }^{1} \cdot$ Adhirath S. Wagh $^{1} \cdot$ Abhishek Sharma $^{2} \cdot$ Vishnu Pareek $^{1} \cdot$ Yun Yu$^{1} \cdot$ Jyeshtharaj B. Joshi ${ }^{3}$
}

Received: 20 June 2021 / Accepted: 29 December 2021 / Published online: 4 February 2022

(c) Crown 2022

\begin{abstract}
In this work, effect of salt on cellulose pyrolysis behaviour using chemical percolation devolatilization (CPD) model has been investigated. The distributed activation energy model (DAEM) has been used to determine the kinetics of pure and $\mathrm{NaCl}$-loaded cellulose pyrolysis in a thermogravimetric analyser (TGA). A number of these experiments were performed for a range of heating rates $\left(5-100{ }^{\circ} \mathrm{C} \mathrm{min}^{-1}\right)$ and for different concentrations of $\mathrm{NaCl}$ in cellulose $(0.25-2$ mass/\%) which showed a pronounced effect of salt on the primary pyrolysis reactions of cellulose. These data were then used in a twocomponent DAEM to calculate the kinetic parameters for the chemical percolation devolatilization model (CPD) for both pure and $\mathrm{NaCl}$-loaded cellulose. The optimized kinetic parameters for the pure and $\mathrm{NaCl}$-loaded cellulose were used in the CPD model, and the product yield was predicted. The CPD predictions showed that the fraction of gases and char in the pyrolysis products increased in the presence of salt. The amount of char for pure cellulose was $6.97 \%$ which increased to $16.4 \%$ in the presence of $0.25 \% \mathrm{NaCl}$. The amount of gases produced as a result of pure cellulose pyrolysis was $9.63 \%$ and this amount increased with addition of $\mathrm{NaCl}$ to $22.85 \%$ and then further increases with an increase in $\mathrm{NaCl}$ concentration. Amount of tar produced for pure cellulose was $83.4 \%$, and this amount reduced to $60.7 \%$ with addition of $0.25 \% \mathrm{NaCl}$. The presence of $\mathrm{NaCl}$ accelerates cellulose decomposition and favours the formation of gases and char.
\end{abstract}

Keywords Kinetic $\cdot$ Pyrolysis $\cdot$ CPD $\cdot$ Inorganic species $\cdot$ Cellulose $\cdot$ Product yield

\section{Introduction}

Cellulose pyrolysis is a combination of parallel and series reactions. Despite sufficient literature available addressing the mechanism and kinetics of cellulose pyrolysis, still there exist uncertainties for the complete understanding of the decomposition behaviour of this process [1-4]. The parameters which govern the kinetics of these reactions are activation energies and frequency factors. An overview of some of the kinetic models published for cellulose pyrolysis along with kinetic parameters has been presented by Cristina

Vishnu Pareek

v.pareek@curtin.edu.au

1 Western Australian School of Mines: Minerals, Energy and Chemical Engineering, Curtin University, GPO Box U1987, Perth, WA 6845, Australia

2 Department of Chemical Engineering, Manipal University Jaipur, Dehmi Kalan, Jaipur, Rajasthan 303007, India

3 Department of Chemical Engineering, Institute of Chemical Technology, Mumbai, Maharashtra 400019, India
Serbanescu [3]. Among these models, Broido-Shafizadeh [5] is the most frequently used model. Different kinetic models were used by Yang et al. [6] to describe the kinetics of cellulose pyrolysis using TGA and thermogravimetric analysis coupled to Fourier transform infrared spectroscopy (TGAFTIR) experimental data. Bojan Janković has also worked for the kinetic study of biomass and powdered cellulose using Bayesian inference and suggested that this approach can be used for the powdered cellulose pyrolysis [7, 8].

DAEM assumes that solid decomposition is a combination of infinite parallel reactions which may be first or nth-order with different activation energies describing the variation in bond strengths of species, which can be determined using a probabilistic distribution function [9]. This model was proposed by Vand and was then used by Pitt [10] for coal devolatilization and later popularized by Anthony and Howard [11]. Different types of global kinetic models including first-order, nth-order, nucleation and sequential models along with several methods of energy distribution have been reviewed by Burnham and Braun [12]. There are two distinct methods of treating distributed reactivity: (1) 
fitting a set of parallel reactions to either a mathematical or arbitrary distribution and (2) the use of iso-conversional method which is an infinitely sequential method [13]. Friedman method is considered to be the most accurate among all the iso-conversional methods [14].

CPD model is a network model which describes the devolatilization of biomass components on the basis of chemical structure. The CPD model was first used for the devolatilization of coal [15] and was later on implemented to biomass and its components (cellulose, hemicellulose and lignin) $[16,17]$. The model used for biomass is also known as Bio-CPD model. For the implementation of CPD model, two types of parameters are important, structural and kinetic parameters, which have been determined for the individual constituents of biomass [18]. The basic reaction scheme of CPD model is shown in Fig. 1. This scheme has been selected for cellulose devolatilization in this study because this is analogous to the most commonly used Broido-Shafizadeh scheme for cellulose pyrolysis.

Labile bridges $(L)$ break to form an active intermediate $\left(L^{*}\right)$ which is unstable and immediately proceeds to two competitive parallel reactions. In one reaction, two side chains $(\delta)$ are produced which are then converted to light gas $\left(2 g_{1}\right)$. Infinite number of bridges break to form low molecular weight fragments which vaporize to give tar. In the second reaction, the intermediate produces $\left(L^{*}\right)$ stable char $(c)$ and releases light gas $\left(2 g_{2}\right) . k_{\mathrm{b}}$ is the rate of first reaction. Rate of the next two parallel reactions is specified by a ratio as, $\rho=k_{\delta} / k_{\mathrm{c}}$,which is usually taken as a constant [19]. There are different versions of CPD model such as CPD-CP, CPDheat [20] and CPD-nlg [21]. CPD-heat is used in the current work because it requires heating rate as input and calculates particle temperature at every step using that heating rate which is similar to the data produced by TGA. CPD model for biomass was studied for its three components, i.e. cellulose, hemicellulose and lignin individually, and overall product yield was determined as mass average of the yield of the given components $[18,22]$. The model generated results comparable to experimental data; however, effect of inorganic species or ash content present in biomass on the pyrolysis product yield was not considered. Several researchers have performed experiments to study the effect of the

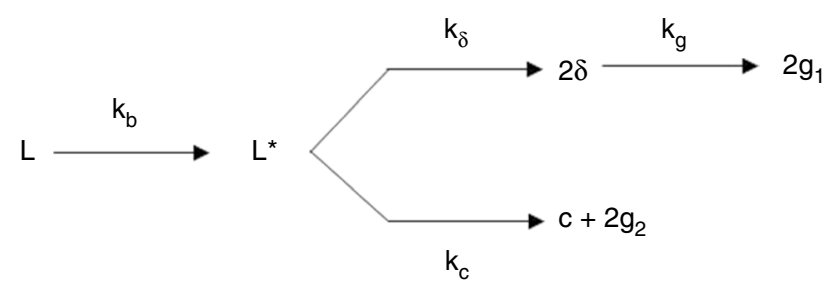

Fig. 1 Reaction scheme for CPD [18] presence of inorganic matter on biomass pyrolysis and have come across a general trend that it increases the char and volatiles yield at the expense of bio-oil yield [23-27]. Raveendran et al. [28] conducted experiments for biomass samples of 12 different types and studied the effect of demineralization and salt-impregnation. The results obtained were as follows: increase in char yield for salt-impregnated samples of coir pith, groundnut shell and rice husk char and liquids yield reduced, while gas yield increased. Varhegyi et al. [29] used thermogravimetric-mass spectrometric studies for salt-added cellulose samples to observe the changes in the decomposition process as well as the product distribution. Different types of salts have different influence on the decomposition of sugar structures at different operating temperatures [30]. Liu et al. [30] proposed that added salts affect the dehydration reactions significantly however, this effect is very less for depolymerization reactions. To reduce the complexity and better understand the effect of salt on pyrolysis reactions, this paper studies the kinetics of pure cellulose and $\mathrm{NaCl}$-loaded cellulose. The cations $\mathrm{K}^{+}, \mathrm{Na}^{+}, \mathrm{Ca}^{2+}$ and $\mathrm{Mg}^{2+}$ have profound effect on the rate of formation of different products as a result of pyrolysis. Majorly, the metal salt $\mathrm{KCl}$ has been used in the literature to study its effect on cellulose and biomass pyrolysis. $\mathrm{NaCl}$ is considered to behave in the same way as $\mathrm{KCl}$; therefore, $\mathrm{NaCl}$ has been used in this work. In the literature, the effect of different salts on biomass decomposition has been studied, and it is clear that they have profound influence on biomass pyrolysis; however, the CPD model does not include the inorganic species. CPD model can be implemented to whole biomass if all the constituents have been considered. This study will help in understanding the decomposition behaviour of saltloaded cellulose using CPD model.

The major objective of this study is to highlight the significance of inorganics while implementing the CPD model to the whole biomass and setting a milestone for future research in this direction. In this regard, the first objective is to propose a strategy to predict the kinetic parameters for CPD model by performing thermogravimetric analysis of the sample and optimization using the DAEM. Secondly, to predict pyrolysis product yield using the CPD model for $\mathrm{NaCl}$-loaded cellulose. CPD model has previously been used for biomass constituents such as cellulose, hemicellulose and lignin, while the effect of inorganic species has never been considered. This work is the first step in understanding the effect of inorganics on pyrolysis product yield by implementing the CPD model to the $\mathrm{NaCl}$-loaded cellulose. In order to achieve these objectives, TGA experiments for pure and $\mathrm{NaCl}$-loaded cellulose were carried out over a wide range of heating rates $\left(5-100^{\circ} \mathrm{C} \mathrm{min}^{-1}\right)$. The TGA data were processed, and kinetic parameters were determined using a two-component DAEM for pure and NaCl-loaded cellulose. In the second part, the distributed activation energy 
and CPD models were coupled by substituting the rate constants $\left(\mathrm{k}_{\mathrm{b}}\right.$ and $\left.\mathrm{k}_{\mathrm{g}}\right)$ calculated by DAEM into the CPD model. The substituted values and CPD-heat model algorithm were then used to predict the pyrolysis products of pure cellulose, and the results were compared with the literature. Once the coupling of DAEM and CPD model was validated for pure cellulose, kinetic parameters obtained for $\mathrm{NaCl}$-loaded cellulose using DAEM were used to evaluate the effect of salts on pyrolysis product profile obtained using CPD-heat model. Flow diagram in Fig. 2 represents the modelling and simulation strategy used in this work.

\section{Materials and methods}

\section{Materials}

Microcrystalline cellulose (Avicel PH-101, SigmaAldrich) was first sieved to obtain the particles in a size range of $\leq 45 \mu \mathrm{m}$, and the results of particle size distribution obtained with a particle size analyser (Mastersizer 2000, Malvern Panalytical, Ltd.) are shown in Table 1. The sample was then washed using deionized water at room temperature to remove any water-soluble compounds which may be present in the sample and dried in an oven at $70{ }^{\circ} \mathrm{C}$. Pure cellulose sample was also tested for ash by combusting the cellulose sample, and no ashes were found in the sample which lead the calculations to be made on dry, ash-free bases (daf). Washed cellulose was then used for the preparation of salt-loaded cellulose. $\mathrm{NaCl}$ was selected for this study as inorganic species, and its effect on pyrolysis product yield was observed. There are several methods in the literature for sample preparation, while wet impregnation method was used in this study [31-33]. Particular amount of $\mathrm{NaCl}$ was dissolved in water to prepare salt solution, and then $2.0 \mathrm{~g}$ of cellulose was added to the solution and stirred for $2 \mathrm{~h}$. This slurry was filtered, and product was dried in the oven at $70{ }^{\circ} \mathrm{C}$. The concentration
Table 1 Particle size distribution for pure cellulose sample

\begin{tabular}{lllll}
\hline Sample & $\begin{array}{l}\text { Volume } \\
\text { weighted } \\
\text { mean, D [3, } \\
4] \mu \mathrm{m}\end{array}$ & $\mathrm{D}(\mathrm{v}, 0.1) \mu \mathrm{m}$ & $\mathrm{D}(\mathrm{v}, 0.5) \mu \mathrm{m}$ & $\mathrm{D}(\mathrm{v}, 0.9) \mu \mathrm{m}$ \\
\hline $\begin{array}{l}\text { Pure cel- } \\
\text { lulose }\end{array}$ & 48.52 & 16.31 & 42.71 & 89.42 \\
\hline
\end{tabular}

of $\mathrm{NaCl}$ loaded was taken as mol of salt $/ \mathrm{mol}$ of cellulose. Salt concentration was varied between 0 and 2.0 mass $/ \%$, and five different samples were prepared.

\section{Equipment and experimental procedure}

PerkinElmer thermogravimetric analyser (TGA-8000) was used for pyrolysis at a temperature ramp of $100-700{ }^{\circ} \mathrm{C}$, for different heating rates in the range of 5 to $100{ }^{\circ} \mathrm{C} \mathrm{min}^{-1}$ in the presence of argon (Ar) as an inert gas at a flow rate of $60 \mathrm{~mL} \mathrm{~min}^{-1}$. The heating rates selected for experiments were: 5, 20, 40, 60 and $100{ }^{\circ} \mathrm{C} \mathrm{min}^{-1}$. Minimum (5) and maximum (100) heating rate was selected to validate the kinetic data from the literature [34]. Each set of experiments has been repeated three times to minimize the error. Mass loss data were generated for these heating rates for both pure and $\mathrm{NaCl}$-loaded cellulose. A weighed sample of 3.0-4.0 mg was put in the crucible, and then temperature program was run using different heating rates. All the samples of $\mathrm{NaCl}$-loaded cellulose were combusted in the presence of oxygen to determine the organic fraction of solid residue remaining after pyrolysis. The detailed temperature program is included in supporting information Table S1. The amount of salt residue was determined by making a comparison between the amount of residue left after the decomposition of pure cellulose and $\mathrm{NaCl}$-loaded cellulose. These values are given in Table $\mathrm{S} 2$ of supporting information.
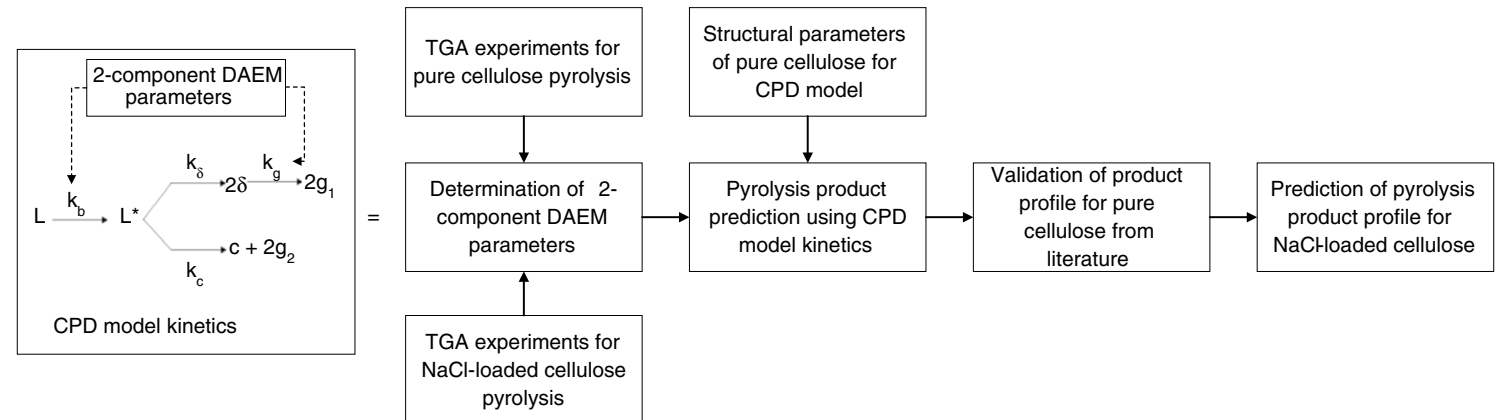

Fig. 2 Strategy for using DAEM and CPD model to predict pyrolysis product composition for pure and NaCl-loaded cellulose 


\section{Modelling and simulations}

To estimate kinetic parameters using DAEM, there are two methods: distribution-free methods and distributionfitting methods. In this work, kinetic parameters have been determined through distribution-fitting method using first-order reaction model written in MATLAB. The basic steps involved for optimization of kinetic parameters are as follows:

1. Raw TGA data were used to calculate conversion $(\alpha)$ using Eq. 1.

2. TGA data smoothing using Savitzky-Golay filter in MATLAB to derive a smooth differential TGA (DTG) curve.

3. Choosing 60 equidistant points of TGA and DTG curves in the non-isothermal region of the data.

4. An initial guess for frequency factor (A) and mean activation energy $\left(\mathrm{E}_{0}\right)$ was taken from the literature.

5. $f(E)$ was assumed to have a Gaussian distribution.

6. An objective function (Eq. 4) was constructed to simultaneously minimize the error between experimental and predicted conversion values obtained for multiple heating rates.

7. Frequency factor $(A)$ and $E_{0}$ were optimized by minimizing the objective function using fmincon in MATLAB.

$$
\alpha_{\mathrm{i}}=\frac{M_{\text {dry }}-M_{\mathrm{t}}}{M_{\text {dry }}-M_{\infty}}
$$

where $\mathrm{M}_{\mathrm{dry}}$ and $\mathrm{M}_{\infty}$ are the initial dry mass of biomass and final mass of residue remaining after completion of pyrolysis reaction, respectively. $\mathrm{M}_{\mathrm{t}}$ is the mass of biomass remaining in the TGA pan at time " $t$ ".

$\mathrm{J}_{1}=\sqrt{\sum_{j=1}^{n} \sum_{i=1}^{m} \frac{\left(\alpha_{\text {expt,ij }}-\alpha_{\text {pred }, \mathrm{ij}}\right)^{2}}{n}}$

$\mathrm{J}_{2}=\sqrt{\sum_{j=1}^{n} \sum_{i=1}^{m} \frac{\left(\left(\frac{d \alpha}{d t}\right)_{\text {expt,ij }}-\left(\frac{d \alpha}{d t}\right)_{\text {pred, }, \mathrm{j}}\right)^{2}}{u_{\mathrm{j}}^{2} n}}$

$\mathrm{J}_{3}=\frac{J_{1}+J_{2}}{2}$

where $n$ is the number of heating rates used simultaneously to fit the kinetic parameters, $m$ is the number of points on each evaluated curve, $u$ is the peak maximum for each DTG curve. The use of $u$ is to normalize the objective function. The Gaussian distribution has been used in this work to predict the range of activation energies because it gives the symmetric data.

Mass loss data, in the non-isothermal region, collected from TGA were used to determine the kinetic parameters at heating rates of $5,20,40,60$ and $100{ }^{\circ} \mathrm{C} \mathrm{min}^{-1}$ using DAEM.

Optimized kinetic parameters were then substituted as input parameters $\left(\mathrm{k}_{\mathrm{b}}\right.$ and $\left.\mathrm{k}_{\mathrm{g}}\right)$ to the CPD model, and overall volatiles yield was compared to the experimental data to validate the model. CPD-heat model was used for this work as it required particle heating rate as an input which was suitable for TGA data. The code for this model is available online [35]. Once the CPD model was validated for pure cellulose using the optimized parameters from distributed activation energy, same strategy was used to predict pyrolysis product profile for $\mathrm{NaCl}$-loaded cellulose.

\section{Results and discussion}

\section{TGA results for pure cellulose}

The first part of the analysis from TGA involved the selection of sample mass. Experiments were performed with different amounts of sample, and results were compared. In the first run, sample mass was taken in the range of $1.2-1.5 \mathrm{mg}$, while in the second run, the mass was increased to $3.5-4.0 \mathrm{mg}$, and mass loss data were collected at different heating rates. The results for the lowest heating rate of $5^{\circ} \mathrm{C} \mathrm{min}^{-1}$ and the highest heating rate of $100{ }^{\circ} \mathrm{C} \mathrm{min}^{-1}$ were compared, which clearly confirmed that difference for conversion " $\alpha$ " and derivative of conversion " $\mathrm{d} \alpha / \mathrm{dt}$ " is not significant for different mass samples. As a result, 3.5-4.0 mg sample mass was selected for further experiments in this study. The graphs of these results are included in Supporting Information Fig. S1.

Conversion $\alpha$ and derivative of conversion $\mathrm{d} \alpha / \mathrm{dt}$ were calculated using mass loss data from TGA. Trends of " $\alpha$ " and "d $\alpha / \mathrm{dt}$ " for all heating rates of 5, 20, 40, 60 and $100{ }^{\circ} \mathrm{C} \mathrm{min}^{-1}$ versus temperature are shown in Fig. 3a and $\mathrm{b}$, respectively.

Conversion increased with an increase in heating rate, which is more prominent from 5 to $20{ }^{\circ} \mathrm{C} \mathrm{min}{ }^{-1}$; however, above $20^{\circ} \mathrm{C} \mathrm{min}^{-1}$, the gap becomes narrow. Peak of derivative of conversion also shifted to higher temperatures with an increase in heating rate. This indicates that in the reaction scheme (shown in Fig. 1), among the two competitive reactions $\left(\mathrm{k}_{\delta}\right.$ and $\left.\mathrm{k}_{\mathrm{c}}\right)$, the rate of side chains formation is more significant which as a result promotes the volatiles formation. The results were same as reported in the literature previously [36]. 
(a)

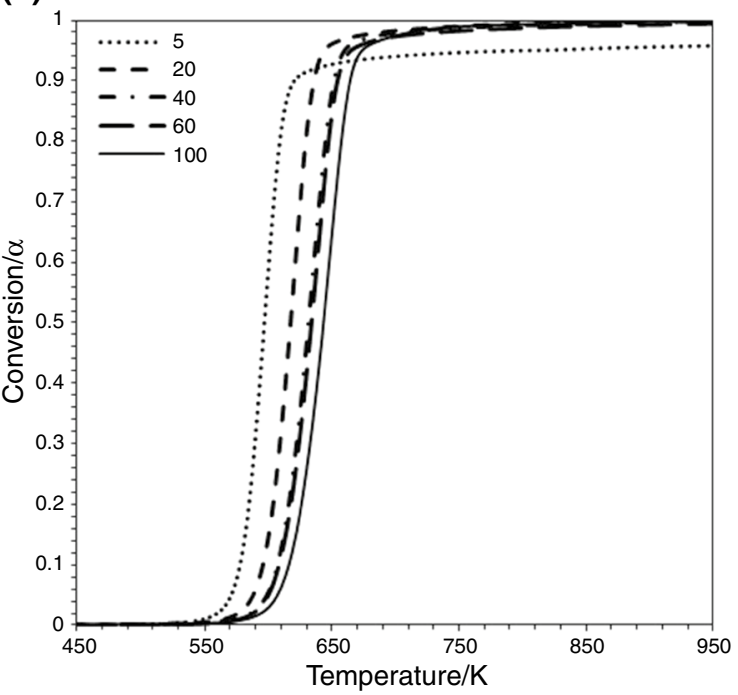

(b)

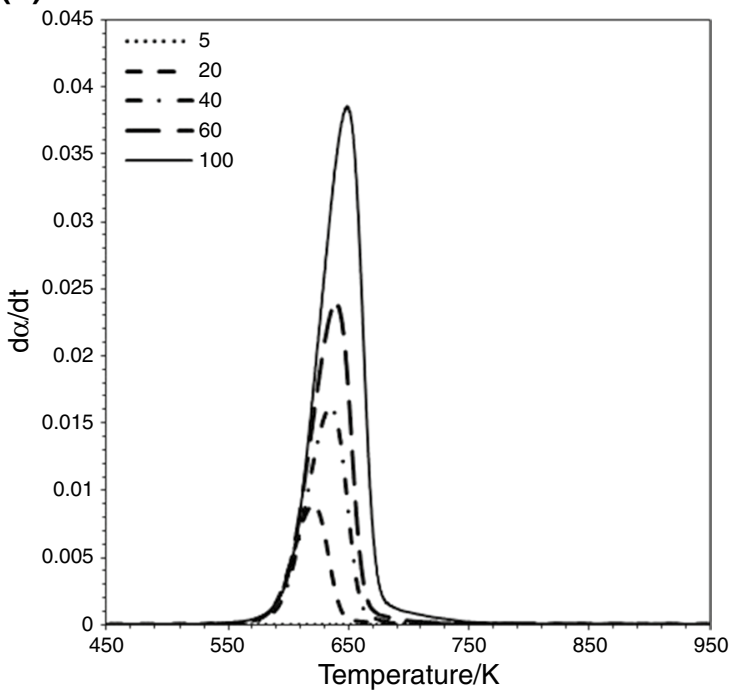

Fig. 3 a Conversion, $\alpha \mathbf{b}$ d $\alpha / d t$ at different heating rates

\section{Kinetic Parameters for pure cellulose using DAEM}

The mass loss data from TGA were further used to determine kinetic parameters using DAEM. Since there are four reactions in the CPD scheme, it is important to know the kinetics of these reactions. Specifying " $\rho$ " as a constant which is the ratio of $k_{\delta} / k_{\mathrm{c}}$, only $k_{\mathrm{b}}$ and $k_{\mathrm{g}}$ need to be determined. For this purpose, two-component modelling scheme was used. Initial guess for the parameters was taken from the literature [16], and then the parameters were optimized. These optimized values and the literature values are shown in Table 2.

Change in the values of frequency factor and standard deviation for the bridge breaking reaction is prominent; however for the gas-phase reaction, values are almost similar. The reason for difference in the values of the standard deviation in bridge breaking activation energy may be the different optimization tool. In this work, two-component DAEM has been used to optimize the parameters; however, Lewis and Fletcher [18] used different approach. The predicted kinetic parameters for CPD model, for pure cellulose, have been validated at three different stages in this manuscript:

Conversion data validation Validation of kinetic parameters predicted from DAEM by comparing it with the conversion data form TGA experiments and conversion data from Dufour et al. [34].

Validation of model After validation of predicted kinetic parameters from DAEM, the same parameters have been used to predict the cellulose pyrolysis product yield using CPD model and have been validated by comparing it with the experimental data and parameters available in the literature [34].

Product Yield data validation The DAEM parameters predicted and validated are further implemented to CPD model to predict the fraction of tar and gasses and are further validated by comparing it with the data available in the literature [37].

These validations are explained in detail in the sections and are presented in Figs. 4, 5 and 6. After the validation of

Table 2 Kinetic parameters for pure cellulose from the literature [16] and this work

\begin{tabular}{lll}
\hline Parameters & Literature values & Optimized values \\
\hline Activation energy for bridge breaking, $\mathrm{E}_{\mathrm{b}} / \mathrm{kJ} \mathrm{mol}^{-1}$ & 231.78 & 232.75 \\
Frequency factor for bridge breaking, $\mathrm{A}_{\mathrm{b}} / \mathrm{s}^{-1}$ & $2.0 \times 10^{16}$ & $8.52 \times 10^{17}$ \\
Standard deviation in bridge breaking activation energy, $\sigma_{\mathrm{b}} / \mathrm{kJ} \mathrm{mol}^{-1}$ & 17.15 & 2.41 \\
Activation energy for gas formation, $\mathrm{E}_{\mathrm{g}} / \mathrm{kJ} \mathrm{mol}^{-1}$ & 256.05 & 255.97 \\
Frequency factor for gas formation, $\mathrm{A}_{\mathrm{g}} / \mathrm{s}^{-1}$ & $3.0 \times 10^{15}$ & $5.51 \times 10^{15}$ \\
Standard deviation in gas release activation energy, $\sigma_{\mathrm{g}} / \mathrm{kJ} \mathrm{mol}^{-1}$ & 33.88 & 33.99 \\
\hline
\end{tabular}


(a)

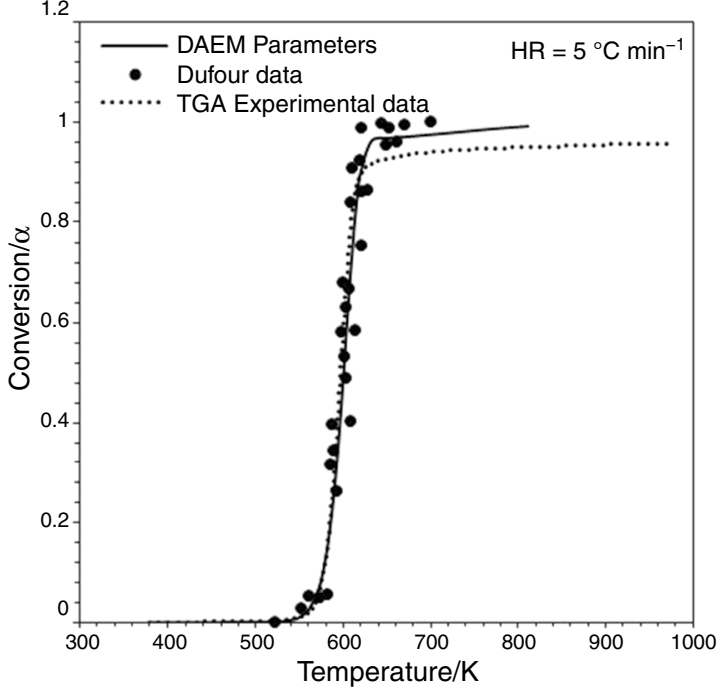

(b)

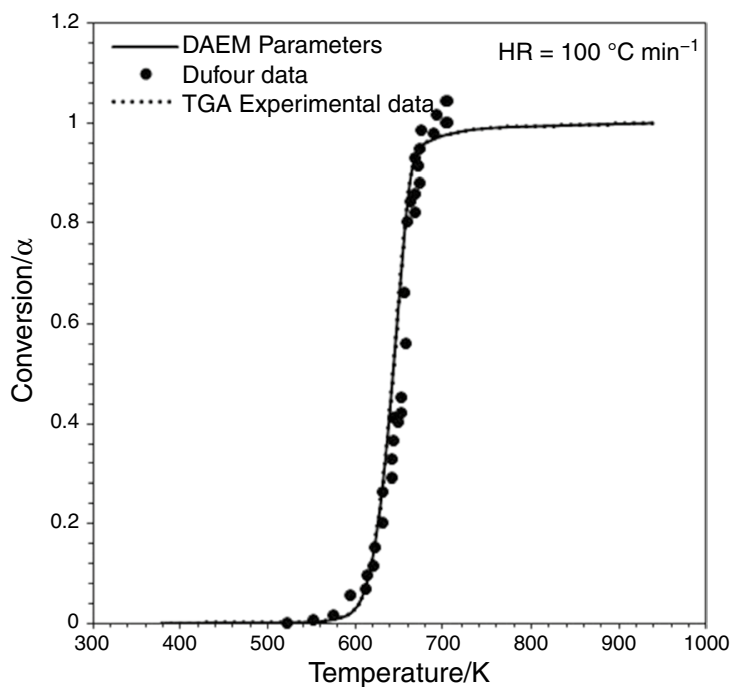

Fig. 4 Comparison of conversion of cellulose obtained from current TGA experiments to the data using DAEM parameters and the literature data [34]

(a)

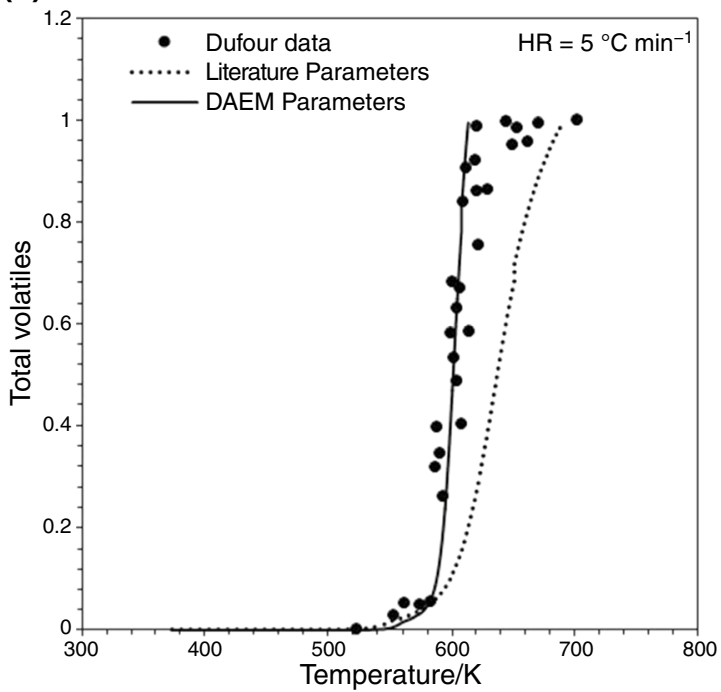

(b)

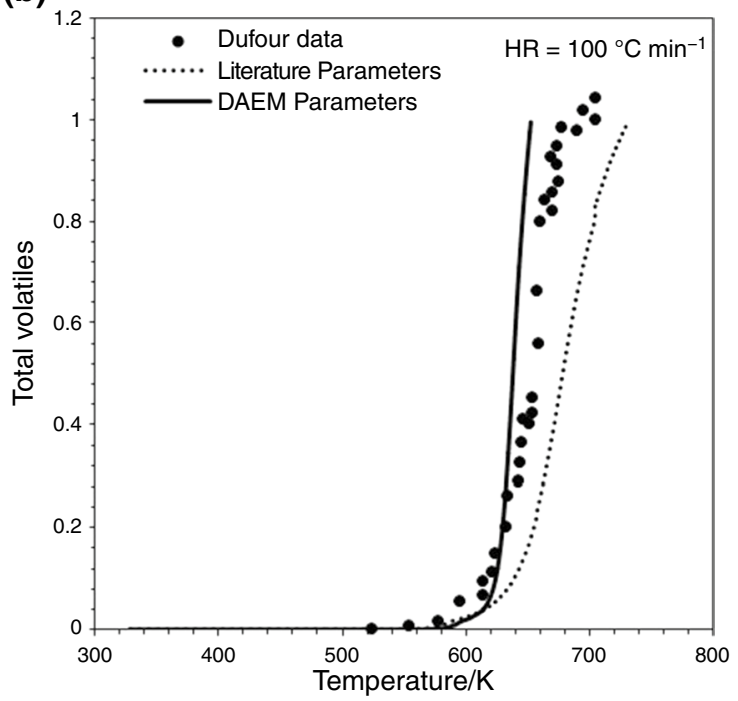

Fig. 5 Validation of DAEM parameters for CPD model at two different heating rates by comparing the DAEM parameters with the literature experimental data [34] and literature parameters [16]

kinetic parameters for CPD model, for pure cellulose, the same methodology has been adopted for $\mathrm{NaCl}$-loaded cellulose to study the effect of salt which is one of the objectives of this research work.
The first part of the study is to validate the kinetic parameters predicted using DAEM. For this purpose, conversion of cellulose calculated from experimental results of TGA has been compared with the conversion obtained 
(a)

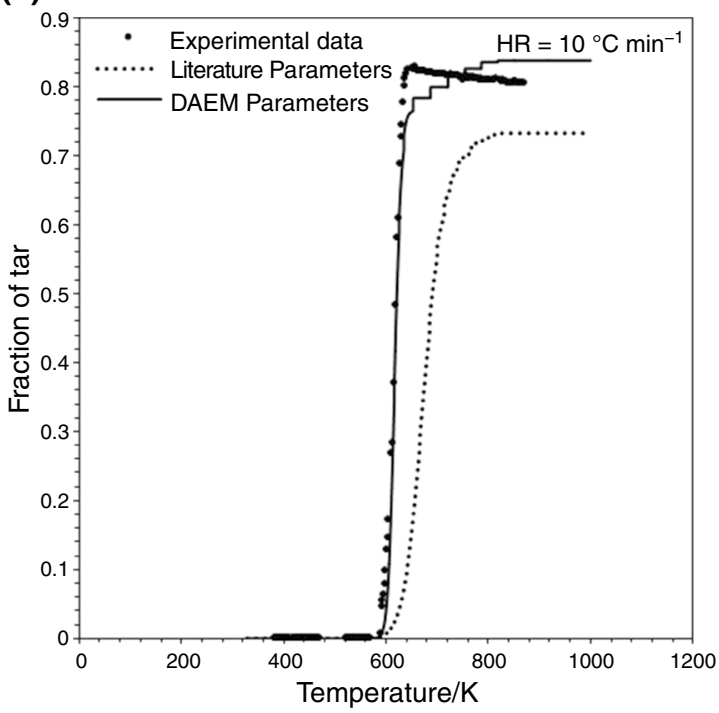

(b)

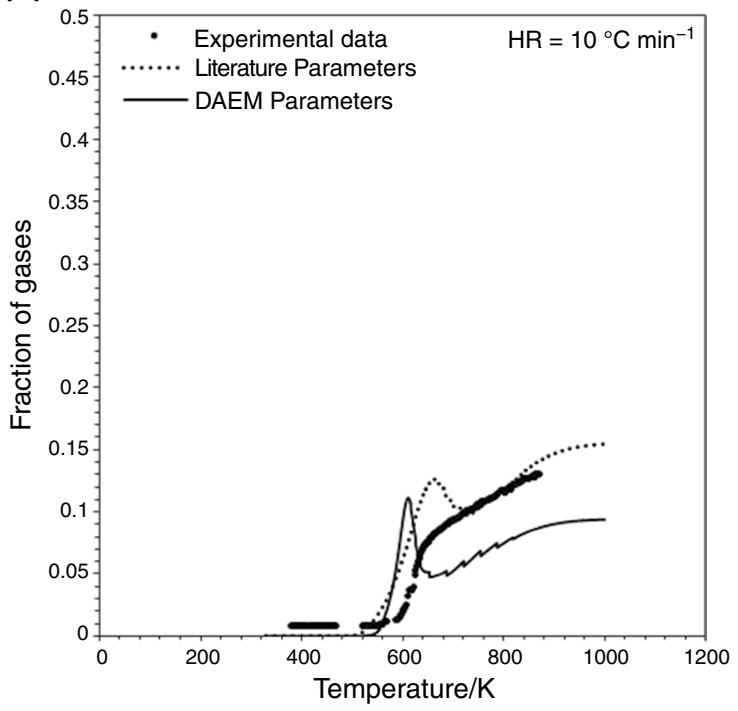

Fig. 6 Fraction of tar and gases obtained from CPD model using optimized DAEM parameters and the literature parameters [37]

Table 3 Structural parameters for cellulose [21]

\begin{tabular}{ll}
\hline Parameters & $\begin{array}{l}\text { Values } \\
\text { for cel- } \\
\text { lulose }\end{array}$ \\
\hline Molecular weight per cluster, $\mathrm{MW}_{\mathrm{cl}}$ & 81 \\
Molecular weight per side chain, $\mathrm{M}_{\delta}$ & 22.7 \\
Per cent intact bridges, $\mathrm{p}_{\mathrm{o}}$ & 1.0 \\
Number of bridges per cluster, $\sigma+1$ & 3.0 \\
\hline
\end{tabular}

from DAEM and data available in the literature for cellulose thermal decomposition in TGA at lower heating rates [38]. Figure $4 \mathrm{a}$ and $\mathrm{b}$ represents the conversions obtained at two different heating rates of 5 and $100{ }^{\circ} \mathrm{C} \mathrm{min}{ }^{-1}$, respectively. These results provide good agreement with the literature data reported earlier and confirm that these optimized parameters can be used for further analysis of cellulose pyrolysis.

\section{Product yield from CPD for pure cellulose}

Kinetic parameters obtained from two-component DAEM dictate the two basic reactions of CPD mechanism, i.e. bridge breaking and gas formation. These were used as input to the CPD model to determine the volatiles, tar and char yield and the yield of bridge population reactions. CPD model was used to predict the total volatiles fraction for cellulose pyrolysis, with two types of input parameters, namely kinetic parameters as shown in Table 1 and the structural parameters shown in Table 3.

The total volatiles fraction from CPD and its comparison with experimental and literature data are shown in Fig. 5a and b. These are represented as: data points are from experimental data available in the literature $[34,38]$, dotted line is the one obtained using already reported kinetic parameters [16], and the solid line is for optimized parameters from DAEM at heating rates of 5 and $100{ }^{\circ} \mathrm{C} \mathrm{min}^{-1}$ from the present work. At low heating rate of $5{ }^{\circ} \mathrm{C} \mathrm{min}^{-1}$, the curves show that result of DAEM parameters is in well-agreement with the experimental data points; however, the literature parameters have more shift towards higher temperature. At higher heating rate of $100{ }^{\circ} \mathrm{C} \mathrm{min}^{-1}$, the experimental data points are in between the curves of literature and DAEM parameters giving a better match to the solid curve. The maximum fraction obtained by the end was 1.0 because of the constant value of $\rho=k_{\delta} / k_{\mathrm{c}}=100$ which was kept high to minimize char formation and maximize tar yield [16].

For the validation of optimized parameters, other than total volatiles, fraction of tar and gases produced was also determined and compared with the literature data [37]. The comparison of these fractions obtained from the literature and from CPD model is shown in Fig. 6a and b. Tar fraction data predicted from DAEM parameters gave an accurate fit with 
Table 4 Comparison of product yield predicted from DAEM with experimental values [38]

\begin{tabular}{lllr}
\hline Yield/\% & Char & Tar & Gases \\
\hline Experimental & 6.46 & 80.44 & 12.93 \\
$\begin{array}{l}\text { Predicted from CPD using parameters } \\
\text { from distributed activation energy }\end{array}$ & 6.82 & 83.79 & 9.39 \\
$\quad$ model & & & \\
\hline
\end{tabular}

the experimental data available in the literature [37]; however, some discrepancies were observed in the trends of gas fraction. The fraction of the gases shows a maxima at around $600 \mathrm{~K}$ because the labile bridges break and form intermediate which is immediately converted into other products through two parallel reactions and the gas formation increases. After a certain time as the intermediate is consumed a decline in the gas fraction is observed, which increases again due to the formation of gases through gas formation reaction which has higher activation energy as compared to bride breaking reaction. The final yield of three products char, tar and gases was in acceptable range when compared with the experimental data and is shown in Table 4. (a)

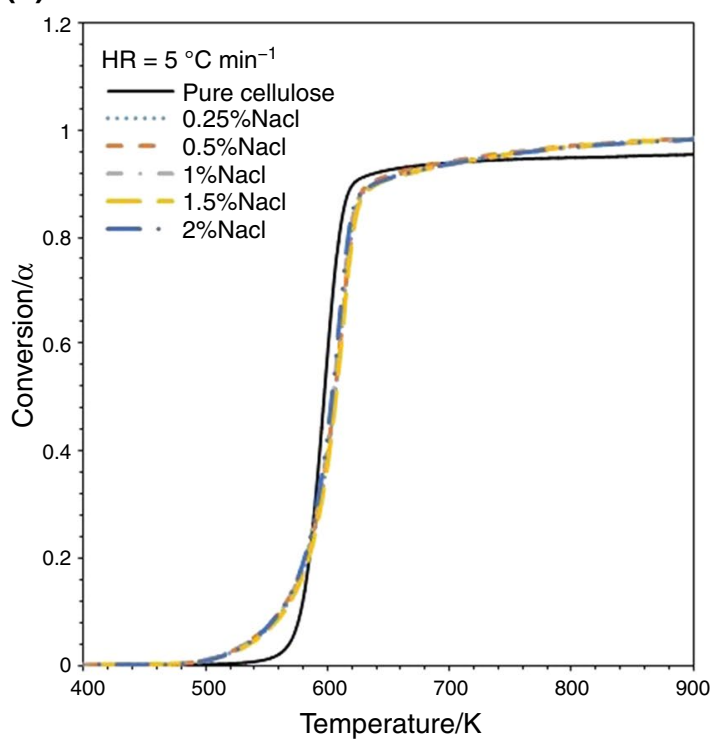

(c)

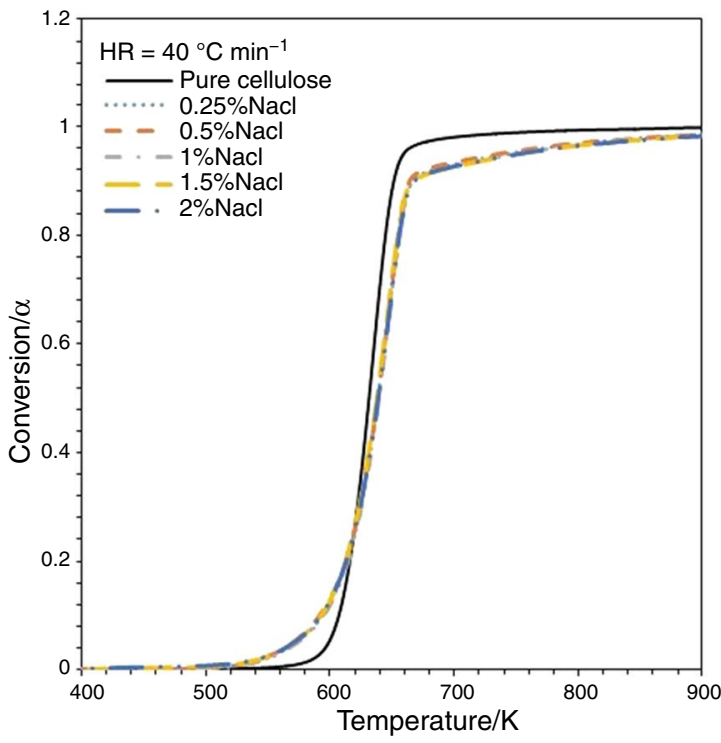

(b)

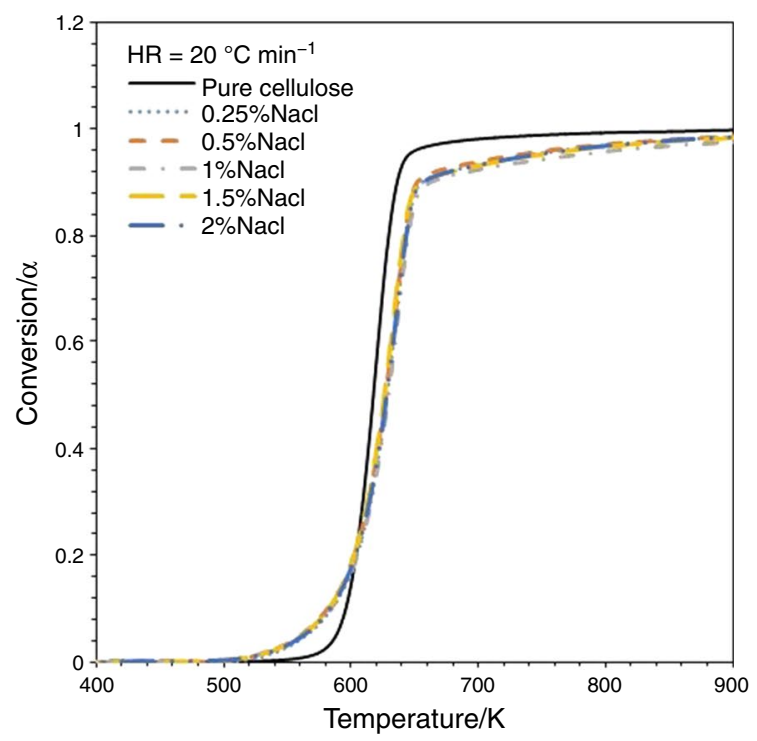

(d)

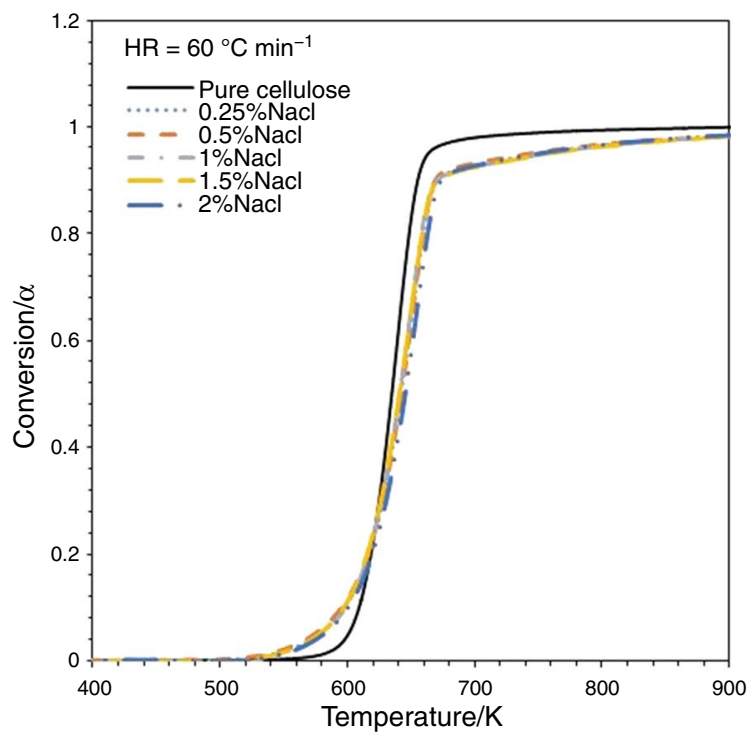

Fig. 7 Conversion of cellulose and $\mathrm{NaCl}$-loaded cellulose for different heating rates 
(a)

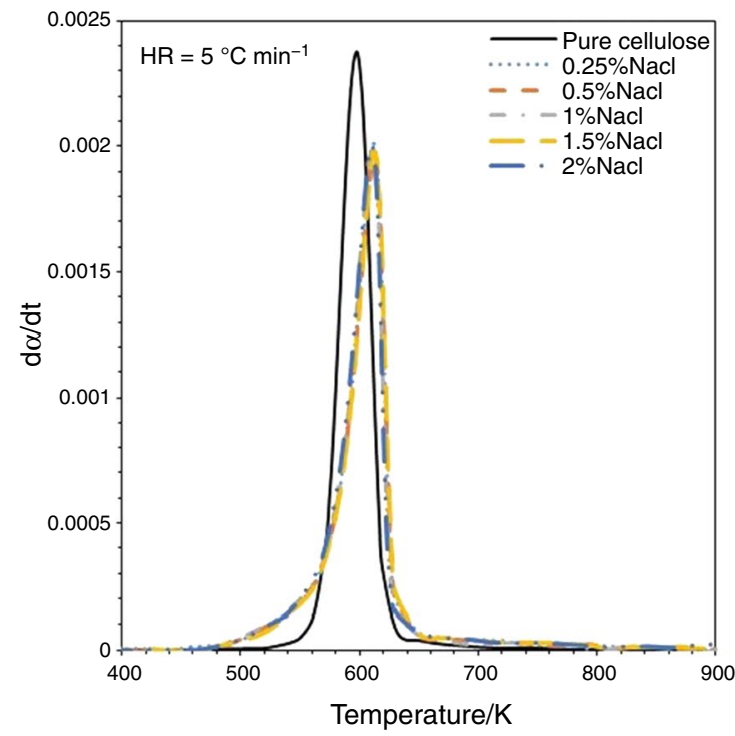

(c)

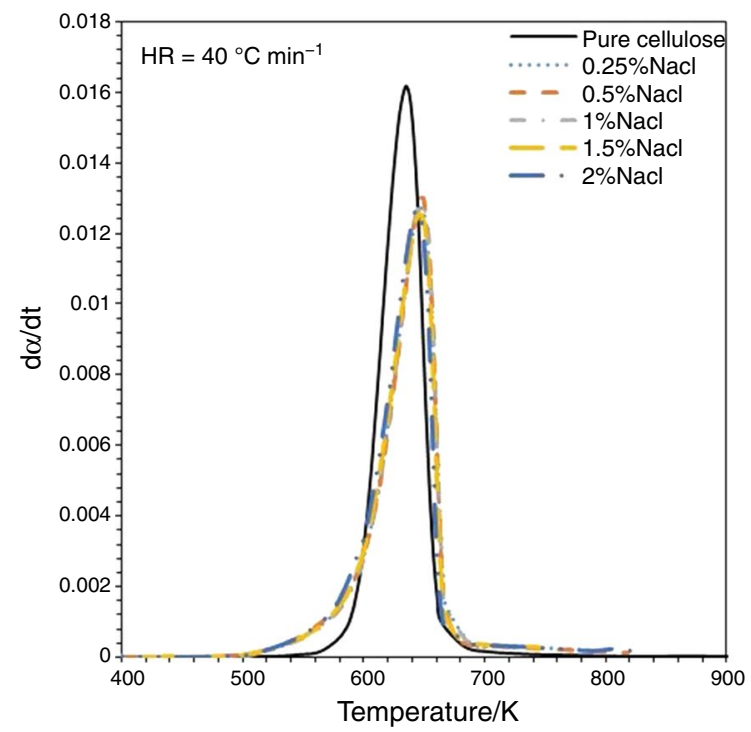

(b)

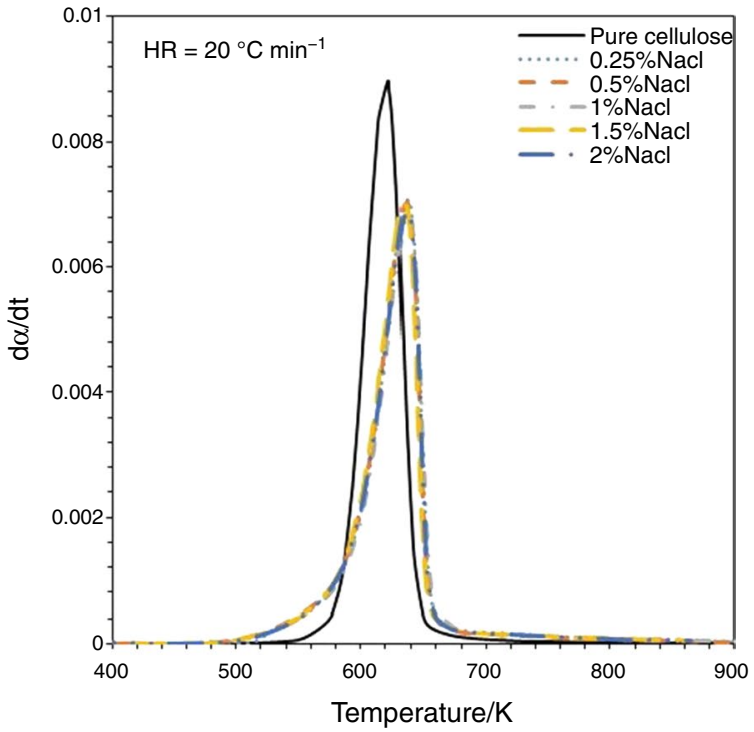

(d)

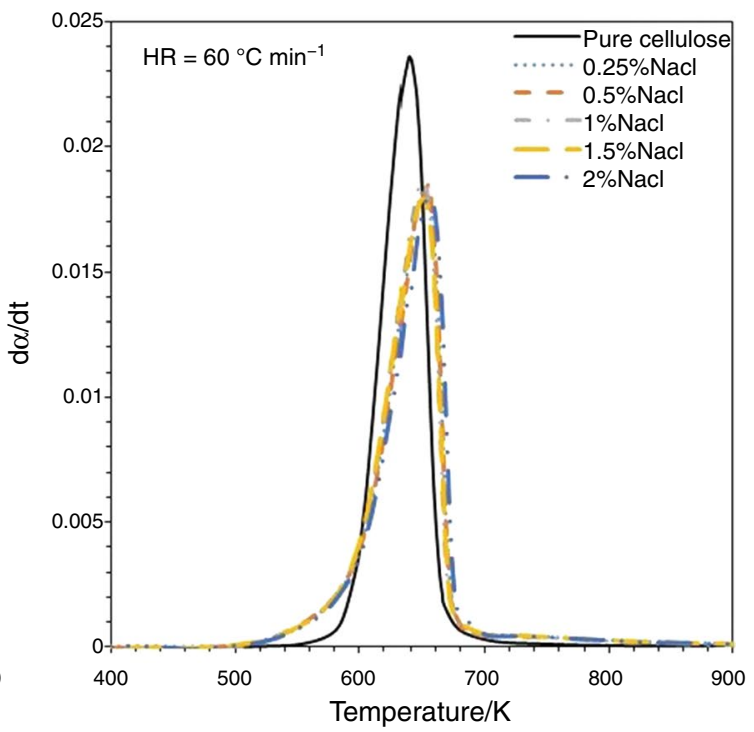

Fig. 8 Rate of conversion for pure cellulose and for different concentrations of $\mathrm{NaCl}$ in cellulose

\section{TGA results for $\mathrm{NaCl}-$ loaded cellulose}

Thermogravimetric analysis can be useful to predict mass loss data for salt-loaded cellulose as well. NaCl-loaded samples of cellulose were run in the TGA using the same temperature program as explained in "Equipment and experimental procedure" section. Mass loss data were collected for the heating rates of $5,20,40$ and $60{ }^{\circ} \mathrm{C} \mathrm{min}-1$ for all five concentrations of $\mathrm{NaCl}$ in cellulose. The conversion, " $\alpha$ " and derivative of conversion, " $\mathrm{d} \alpha / \mathrm{dt}$ " are shown in Figs. 7 and 8, respectively. Figure 7 shows that the cures for the cellulose and $\mathrm{NaCl}$-loaded samples shift towards higher 
temperature with increasing heating rates. The shift of the curves for different $\mathrm{NaCl}$-loaded samples is small which can be observed by zooming the temperature axis between 500 and $700{ }^{\circ} \mathrm{C}$. Conversion of cellulose is supressed in the presence of $\mathrm{NaCl}$ (Fig. 7). At heating rate of $5{ }^{\circ} \mathrm{C} \mathrm{min}^{-1}$, final conversion of $\mathrm{NaCl}$-loaded cellulose surpasses the pure cellulose (Fig. 7a). For all other heating rates of 20, 40 and $60{ }^{\circ} \mathrm{C} \mathrm{min}^{-1}$, the final conversion of $\mathrm{NaCl}$-loaded cellulose lies below the pure cellulose curve (Fig. 7b, c, d).

Figure 8 shows that the presence of $\mathrm{NaCl}$ has also reduced the rate of conversion for cellulose. The maxima of pure cellulose rate curve is higher than the maxima of $\mathrm{NaCl}$-loaded curves; this difference is small at a heating rate of $5{ }^{\circ} \mathrm{C} \mathrm{min}-1$ and increases for the heating rates of 20,40 and $60{ }^{\circ} \mathrm{C} \mathrm{min}^{-1}$, while increase in salt concentration shows negligible shift in the curve. In pyrolysis

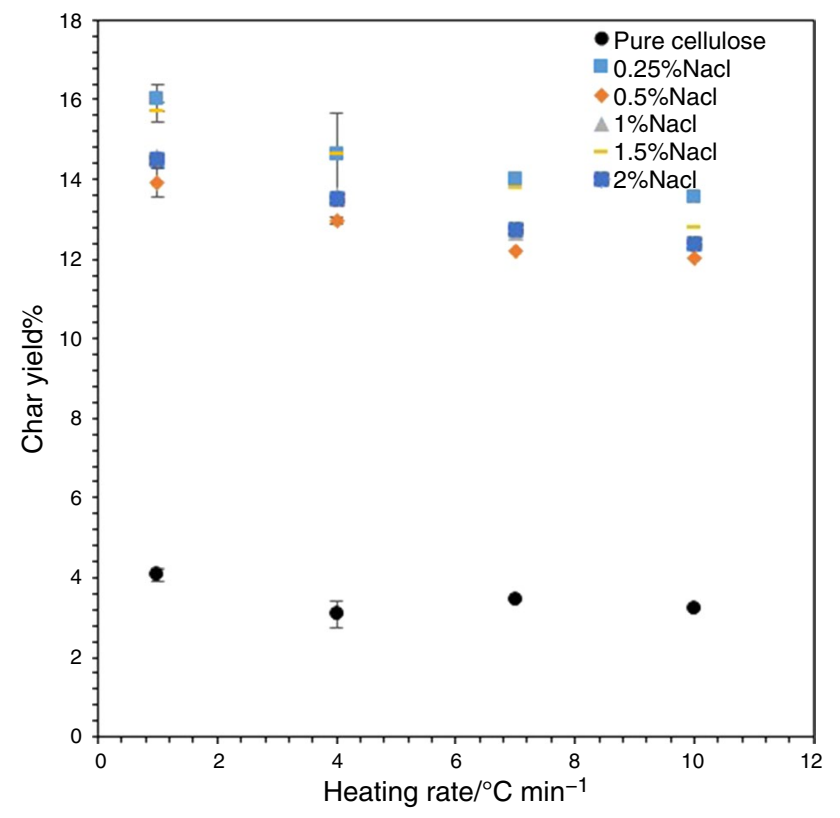

Fig. 9 Effect of the presence of $\mathrm{NaCl}$ on char yield determined on dry, ash-free basis (daf) of $\mathrm{NaCl}$-loaded cellulose, $\mathrm{Na}^{+}$has major contribution towards binding with the original cellulose matrix and neutral species to form $\mathrm{Na}^{+}$-complexes, while chloride will volatilize and become a part of gaseous phase. The catalytic effect of $\mathrm{Na}^{+}$on the reactions as well as product species has already been reported in the literature in detail using mechanistic model $[39,40]$. Mechanistic studies showed that same chemical species were produced in the pyrolysis of pure cellulose and $\mathrm{NaCl}$-loaded cellulose but the kinetics were different. Fraction of char produced at the end of pyrolysis has been calculated to study the effect of the presence of $\mathrm{NaCl}$ in cellulose. Char yield determined for pure cellulose was around $3-4 \%$, while addition of $\mathrm{NaCl}$ increased the char yield up to $14-16 \%$ which is consistent with already reported data in the literature [25, 41]. Figure 8 shows that increase in heating rate decreases the char yield produced for different $\mathrm{NaCl}$-loaded cellulose samples $(0.25-2.0 \%)$ and shifts the rate of conversion towards higher temperature.

Effect of increase in salt concentration on the char yield did not follow an increasing or decreasing pattern. At low concentrations, i.e. $0.25 \% \mathrm{NaCl}$ in cellulose, the char yield was maximum, and for all the other concentrations, it may increase or decrease (Fig. 9). To predict the deviation from the true value, standard deviation error bars have been added. Detailed product analysis of cellulose pyrolysis in the presence of inorganic salts performed by Patwardhan et al. [42] explained that increase in salt concentration decreases the formation of certain products such as levoglucosan and 5-hydroxymethyl furfural, while yield of other products such as formic acid, glycolaldehyde, acetol and 2-furaldehyde first increases and then decreases. But this is also shown that the product yield does not change significantly after a certain amount, and effect of salt concentration becomes constant. Yield of char and total volatiles for pure and NaCl-loaded cellulose obtained at different heating rates is given in Table 5. Figure 10 represents a sharp increase in char yield for $\mathrm{NaCl}$ concentrations as $0-0.25 \%$ for all heating rates, while the average of the yield remains constant in between

Table 5 Pyrolysis product yield for pure cellulose and different concentrations of $\mathrm{NaCl}$ in cellulose at different heating rates

\begin{tabular}{|c|c|c|c|c|c|c|c|c|}
\hline \multirow{3}{*}{$\begin{array}{l}\text { Sample } \\
\text { Heating rate }\end{array}$} & \multicolumn{8}{|c|}{ Pyrolysis product yield } \\
\hline & \multicolumn{2}{|c|}{$5^{\circ} \mathrm{C} \min ^{-1}$} & \multicolumn{2}{|c|}{$20{ }^{\circ} \mathrm{C} \min ^{-1}$} & \multicolumn{2}{|c|}{$40{ }^{\circ} \mathrm{C} \min ^{-1}$} & \multicolumn{2}{|c|}{$60^{\circ} \mathrm{C} \mathrm{min}-1$} \\
\hline & $\begin{array}{l}\text { Volatiles/ } \\
\text { mass/\% }\end{array}$ & Char/mass/\% & $\begin{array}{l}\text { Volatiles/ } \\
\text { mass/\% }\end{array}$ & Char/mass/\% & $\begin{array}{l}\text { Volatiles/ } \\
\text { mass } / \%\end{array}$ & Char/mass/\% & $\begin{array}{l}\text { Volatiles/ } \\
\text { mass/\% }\end{array}$ & Char $/$ mass $/ \%$ \\
\hline Pure Cellulose & 95.93 & 4.06 & 96.91 & 3.09 & 96.56 & 3.44 & 96.78 & 3.22 \\
\hline Cellulose $+0.25 \% \mathrm{NaCl}$ & 83.97 & 16.03 & 85.36 & 14.64 & 85.99 & 14.01 & 86.45 & 13.55 \\
\hline Cellulose $+0.5 \% \mathrm{NaCl}$ & 86.10 & 13.90 & 87.03 & 12.97 & 87.81 & 12.19 & 87.99 & 12.01 \\
\hline Cellulose $+1.0 \% \mathrm{NaCl}$ & 85.44 & 14.56 & 86.40 & 13.60 & 87.37 & 12.63 & 87.85 & 12.15 \\
\hline Cellulose $+1.5 \% \mathrm{NaCl}$ & 84.32 & 15.68 & 85.37 & 14.63 & 86.22 & 13.78 & 87.24 & 12.76 \\
\hline Cellulose $+2.0 \% \mathrm{NaCl}$ & 85.50 & 14.50 & 86.43 & 13.57 & 87.25 & 12.75 & 87.64 & 12.36 \\
\hline
\end{tabular}




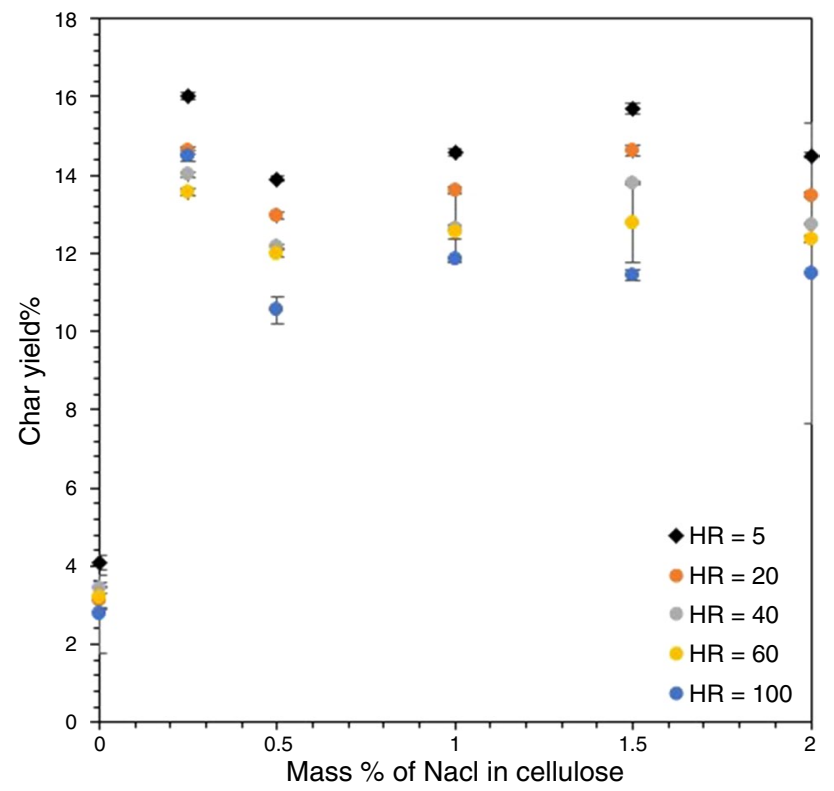

Fig. 10 Char yield for different $\mathrm{NaCl}$ concentrations in cellulose (daf) at heating rates $\left(5-100{ }^{\circ} \mathrm{C} \mathrm{min}^{-1}\right)$

0.5 and $2.0 \%$ of $\mathrm{NaCl}$. With increase in heating rate from 5 to $100{ }^{\circ} \mathrm{C} \mathrm{min}^{-1}$, the char yield decreases as expected. Error bars represent the deviation which is minimum for most of the data points.

\section{Kinetic parameters from DAEM for $\mathrm{NaCl}$-loaded cellulose}

Inorganic species added to cellulose do not change the cellulose structure or reaction mechanism; however, they affect the reaction kinetics $[39,40]$ and specifically they change the relative weighting of different pathways in the same reaction network. Two-component DAEM was used to predict the kinetic parameters for $\mathrm{NaCl}$-loaded cellulose samples. Initial guess was taken from the values of pure cellulose and then optimized for different concentrations of $\mathrm{NaCl}$. The parameters obtained are shown in Table 6.

For bridge breaking reaction, there is a decrease in activation energy, $\mathrm{E}_{\mathrm{b}}$ as well frequency factor, $\mathrm{A}_{\mathrm{b}}$ with the addition of $\mathrm{NaCl}$ to pure cellulose, while the values then increase with the increase in $\mathrm{NaCl}$ concentration. The value of standard deviation of bridge breaking, $\sigma_{b}$, does not follow any increasing or decreasing trend. For gas formation reaction, activation energy, $E_{g}$, frequency factor, $A_{g}$ and the standard deviation of gas formation, $\sigma_{\mathrm{g}}$ decreases for $\mathrm{NaCl}$-loaded cellulose as compared to the pure cellulose; however, this trend is not linear with the increase in salt concentration.

\section{Product yield from CPD for $\mathrm{NaCl}$-loaded cellulose}

The parameters obtained from DAEM were used to predict the product yield. To implement CPD model, two types of parameters are required as input data: structural and kinetic parameters. Structural parameters were kept same as that of pure cellulose (Table 3) making an assumption that $\mathrm{NaCl}$ induced to cellulose does not alter the structural configuration of cellulose [16], while kinetic parameters were predicted using DAEM. Among the four reactions of CPD scheme, kinetics of bridge breaking and gas forming reactions were predicted, and the compositional ratio, $\rho$, was also optimized. As it was taken 100 for pure cellulose which will not be true for $\mathrm{NaCl}$-induced cellulose [16]. So, a value of " $\rho$ " other than the maximum value was required to determine product yield. While finding an optimum of " $\rho$ ", it was observed that this value had a very little effect above 3-100 but the change in this value below 1.0 was highly significant; hence, an optimized value of 2.0 was selected for this work. Results for this analysis are compared in Fig. 11.

Table 6 Predicted kinetic parameters using distributed activation energy model for different mixtures of cellulose and $\mathrm{NaCl}$

\begin{tabular}{lllcccc}
\hline Kinetic parameters & Pure Cellulose & 0.25 mass $/ \% \mathrm{NaCl}$ & 0.5 mass $/ \% \mathrm{NaCl}$ & 1 mass $/ \% \mathrm{NaCl}$ & $1.5 \mathrm{mass} / \% \mathrm{NaCl}$ & $2 \mathrm{mass} / \% \mathrm{NaCl}$ \\
\hline $\mathrm{E}_{\mathrm{b}} / \mathrm{kJ} \mathrm{mol}^{-1}$ & 232.75 & 228.65 & 225.84 & 231.07 & 230.30 & 230.95 \\
$\mathrm{~A}_{\mathrm{b}} / \mathrm{s}^{-1}$ & $8.52 \times 10^{17}$ & $1.71 \times 10^{17}$ & $1.06 \times 10^{17}$ & $2.80 \times 10^{17}$ & $2.55 \times 10^{17}$ & $2.89 \times 10^{17}$ \\
$\sigma_{\mathrm{b}} / \mathrm{kJ} \mathrm{mol}^{-1}$ & 2.41 & 2.71 & 3.32 & 2.26 & 2.30 & 2.98 \\
$\mathrm{E}_{\mathrm{g}} / \mathrm{kJ} \mathrm{mol}^{-1}$ & 255.97 & 249.28 & 254.54 & 248.93 & 250.01 & 250.04 \\
$\mathrm{~A}_{\mathrm{g}} / \mathrm{s}^{-1}$ & $5.51 \times 10^{15}$ & $1.97 \times 10^{19}$ & $1.5 \times 10^{19}$ & $1.56 \times 10^{19}$ & $1.59 \times 10^{19}$ & $1.32 \times 10^{19}$ \\
$\sigma_{\mathrm{g}} / \mathrm{kJ} \mathrm{mol}^{-1}$ & 33.99 & 25.97 & 34.03 & 22.25 & 21.91 & 0.71 \\
$\mathrm{w}_{\mathrm{c}}$ & 0.96 & 0.76 & 0.83 & 0.70 & & 0.73 \\
\hline
\end{tabular}


(a)

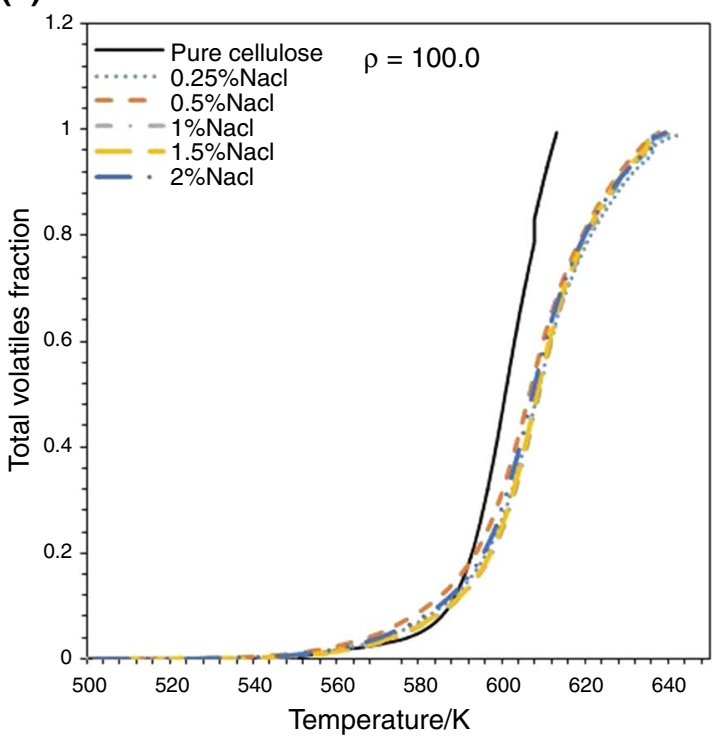

(b)

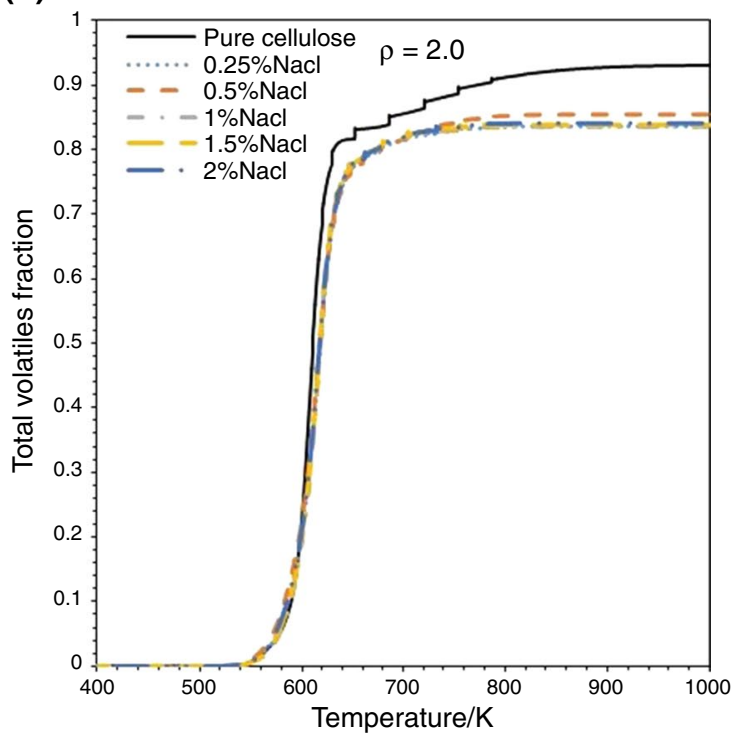

Fig. 11 Comparison of total volatiles fraction at two different values of $\rho$

The graph (a) of Fig. 11 shows that at maximum value of $\rho=100$, the maximum amount of volatiles will be produced reducing the char to a minimum value. For pure cellulose, the curve is approaching to one which remains same for all other samples having $\mathrm{NaCl}$. For $\mathrm{NaCl}$-loaded cellulose, the curve has a huge shift towards higher temperature and reaches maximum fraction at around $640 \mathrm{~K}$. Variation in the value of $\rho$ changes the product distribution. For a value of $\rho=2$, fraction of total volatiles from pure cellulose was maximum around 0.9; however, it decreased to 0.835 with $0.25 \%$ of $\mathrm{NaCl}$. The fractions of three products of cellulose pyrolysis were also determined which are shown in Fig. 12.

The amount of char residue at the end of the simulation for pure cellulose was $6.97 \%$, and this amount increased to $16.4 \%$ for $0.25 \% \mathrm{NaCl}$ in cellulose. The amount of char for all the other salt concentrations is shown in Table 6 . The amount of gases produced as a result of pure cellulose pyrolysis was $9.63 \%$, and this amount increased with addition of $\mathrm{NaCl}$ to $22.85 \%$, and then further increases with increase in $\mathrm{NaCl}$ concentration which is given in Table 6 .
Amount of tar produced for pure cellulose was $83.4 \%$, and this amount reduced to $60.7 \%$ with addition of $0.25 \%$ $\mathrm{NaCl}$. For all other $\mathrm{NaCl}$-induced samples, the amount of tar produced in the presence of different salt concentrations is shown in Table 7. These result correlate to data available in the literature stating that the presence of $\mathrm{NaCl}$ accelerates the cellulose decomposition and favours the formation of gases and char [39].

The results given in Table 7 can be compared to the literature data available. Patwardhan et al. [24] performed experiments for pure and salt-added cellulose in a micropyrolyser at the heating rates of $>2000{ }^{\circ} \mathrm{C} \mathrm{min}^{-1}$. The char yield obtained from these high heating rate experiments for pure cellulose was $5.35 \pm 3.54 \%$, and addition of $0.1 \%$ and $1.0 \% \mathrm{NaCl}$ to the cellulose increased the char yield to 6.76 and $9.77 \%$, respectively. Char yield for pure cellulose is comparable; however, the char yield for $\mathrm{NaCl}$-loaded cellulose in TGA experiments is higher because at low heating rate, the sample will spend more time in the reactor and will promote charring reactions. Even at higher heating rates, the amount of char produced is significant 


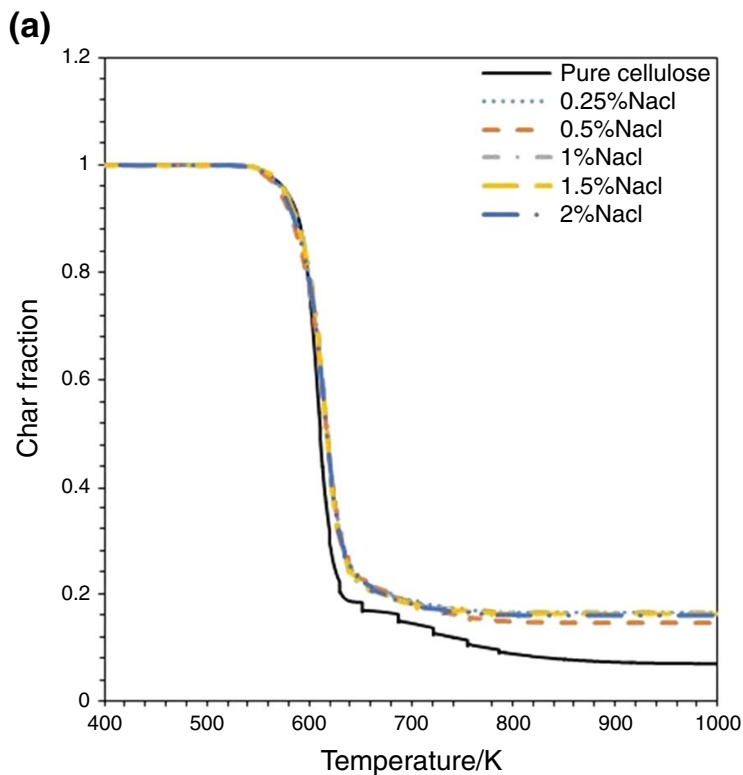

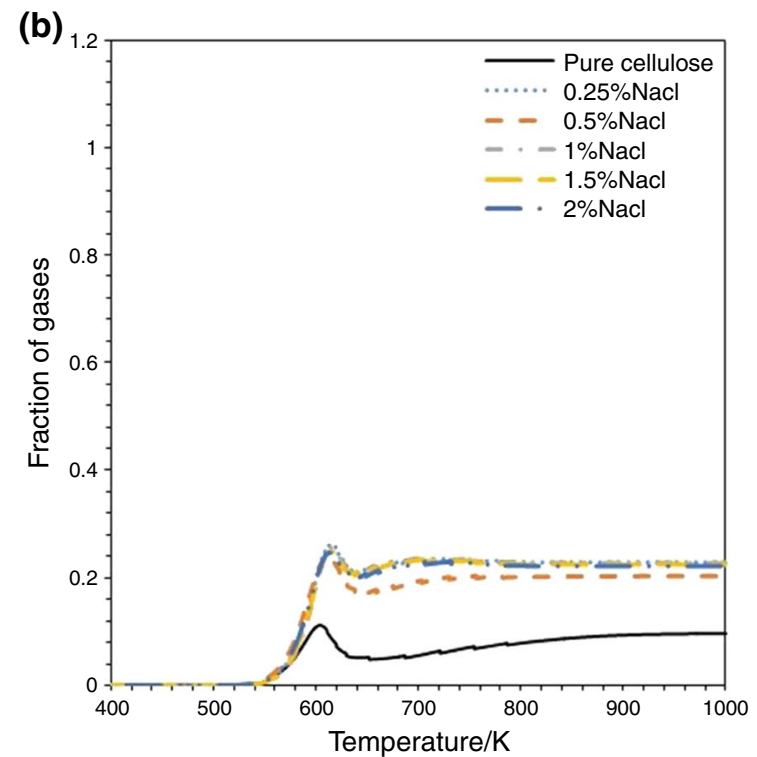

Fig. 12 Char, gas and tar fraction from CPD using optimized parameters

Table 7 Pyrolysis product yield for pure and $\mathrm{NaCl}$-loaded cellulose using CPD

\begin{tabular}{llrr}
\hline Sample & \multicolumn{3}{l}{ Pyrolysis Product Yield/\% } \\
\cline { 2 - 4 } Heating Rate & \multicolumn{2}{l}{$1{ }^{\circ} \mathrm{C} \mathrm{\textrm {min } ^ { - 1 }}$} & \\
\cline { 2 - 4 } & \multicolumn{1}{l}{ Tar } & Gases & Char \\
\hline Pure cellulose & 83.40 & 9.63 & 6.97 \\
Cellulose $+0.25 \% \mathrm{NaCl}$ & 60.70 & 22.85 & 16.45 \\
Cellulose $+0.5 \% \mathrm{NaCl}$ & 65.26 & 20.20 & 14.54 \\
Cellulose $+1.0 \% \mathrm{NaCl}$ & 60.62 & 22.90 & 16.48 \\
Cellulose $+1.5 \% \mathrm{NaCl}$ & 61.19 & 22.57 & 16.24 \\
Cellulose $+2.0 \% \mathrm{NaCl}$ & 61.79 & 22.22 & 15.99 \\
\hline
\end{tabular}

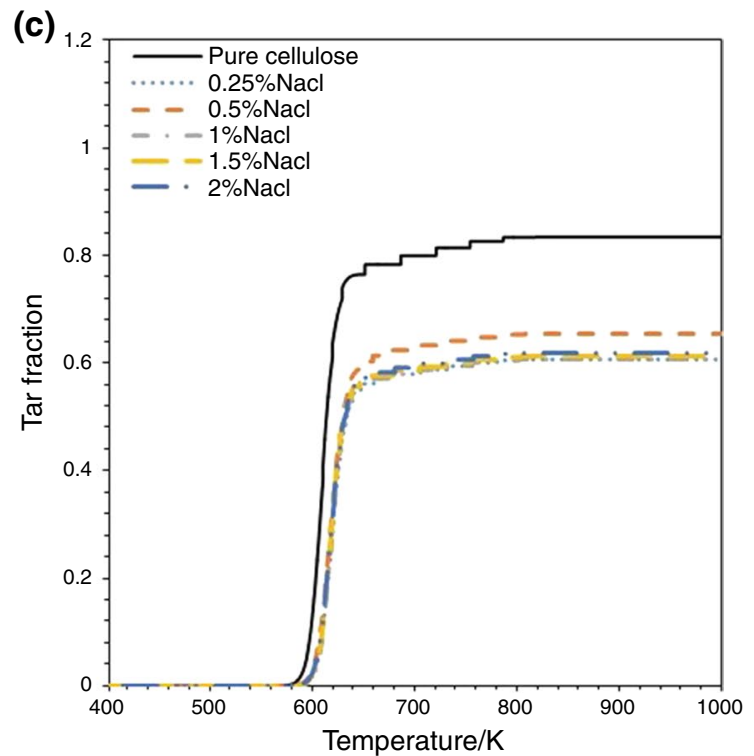

which indicates that the inorganic species have a profound effect on the cellulose pyrolysis at lower and higher heating rates and should be taken into consideration while modelling the cellulose pyrolysis.

\section{Conclusions}

Kinetic parameters to be used as input data for CPD model have been determined using thermogravimetric analysis (TGA) and DAEM. The parameters obtained for pure cellulose have a reasonable consistency with the literature data. Once validated, the same methodology was used to 
determine the kinetics of $\mathrm{NaCl}$-loaded cellulose. The effect of inorganic species specifically $\mathrm{NaCl}$ on the pyrolysis of cellulose was studied by producing $\mathrm{NaCl}$-loaded cellulose using wet impregnation method. The presence of inorganic salts especially the cations $\left(\mathrm{Na}^{+}\right)$supresses the volatile formation by increasing the char and gas yield which has been confirmed from mass loss data collected from TGA. For pure cellulose, char yield at the end of pyrolysis was $3-4 \%$; however, this percentage increased to $14-16 \%$ for $\mathrm{NaCl}$-loaded cellulose. Activation energy, frequency factor and standard deviation of activation energy were optimized for bridge breaking and gas forming reactions of chemical percolation devolatilization (CPD) scheme for pure and NaCl-loaded cellulose. These optimized parameters were then implemented to CPD model, and char, tar and gas yield was predicted which showed an increase in the char and fraction of gases and decrease in tar yield in the presence of $\mathrm{NaCl}$. This leads to the conclusion that while modelling biomass pyrolysis, inorganics should not be neglected as they have a significant effect on the product yield, and future work must incorporate these species and the mutual interaction among the constituents of biomass.

Supplementary Information The online version contains supplementary material available at https://doi.org/10.1007/s10973-021-11192-5.

Acknowledgements The authors acknowledge Prof. Hongwei Wu for his contribution in this work. The authors also acknowledge Curtin University, University of Engineering and Technology and Faculty Development Program of HEC from Pakistan Government, for the support to her PhD studies.

Funding Open Access funding enabled and organized by CAUL and its Member Institutions. This study was funded by Curtin University, University of Engineering and Technology and Faculty Development Program of HEC from Pakistan Government.

\section{Declarations}

Conflict of interest The authors declare that they have no conflict of interest.

Open Access This article is licensed under a Creative Commons Attribution 4.0 International License, which permits use, sharing, adaptation, distribution and reproduction in any medium or format, as long as you give appropriate credit to the original author(s) and the source, provide a link to the Creative Commons licence, and indicate if changes were made. The images or other third party material in this article are included in the article's Creative Commons licence, unless indicated otherwise in a credit line to the material. If material is not included in the article's Creative Commons licence and your intended use is not permitted by statutory regulation or exceeds the permitted use, you will need to obtain permission directly from the copyright holder. To view a copy of this licence, visit http://creativecommons.org/licenses/by/4.0/.

\section{References}

1. Antal MJ. Cellulose pyrolysis kinetics: the current state of knowledge. Ind Eng Chem Res. 1995;34:703-17.

2. Shen D, Xiao R, Gu S, Zhang H. The overview of thermal decomposition of Cellulose in lignocellulosic biomass. Cellul - Biomass Convers [Internet]. 2013;193-226. Available from: http://www. intechopen.com/books/cellulose-biomass-conversion/the-overv iew-of-thermal-decomposition-of-cellulose-in-lignocellulosicbiomass.

3. Şerbănescu C. Kinetic analysis of cellulose pyrolysis: a short review. Chem Pap. 2014;68:847-60.

4. Mayes HB, Broadbelt LJ. Unraveling the reactions that unravel cellulose. J Phys Chem A. 2012;116:7098-106.

5. Bradbury AGW, Sakai Y, Shafizadeh F. Kinetic model for pyrolysis of cellulose. J Appl Polym Sci. 1979;23:3271-80.

6. Yang X, Zhao Y, Li R, Wu Y, Yang M. A modified kinetic analysis method of cellulose pyrolysis based on TG-FTIR technique. Thermochim Acta. 2018;665:20-7.

7. Janković B. The pyrolysis process of wood biomass samples under isothermal experimental conditions-energy density considerations: application of the distributed apparent activation energy model with a mixture of distribution functions. Cellulose. 2014;21:2285-314.

8. Janković B. Estimation of the distribution of reactivity for powdered cellulose pyrolysis in isothermal experimental conditions using the Bayesian inference. Cellulose. 2015;22:2283-303.

9. Cai J, Wu W, Liu R. An overview of distributed activation energy model and its application in the pyrolysis of lignocellulosic biomass. Renew Sustain Energy Rev. 2014;36:236-46.

10. PITT, J. G. The kinetic of the evolution of volatile products from coal. Fuel. 1962 [cited 2019 Mar 6];41:267-74. Available from: http://ci.nii.ac.jp/naid/10003393767/en/.

11. Anthony DB, Howard JB. Coal devolatilization and hydrogastification. AIChE J. 1976;22:625-56.

12. Burnham AK, Braun RL. Global kinetic analysis of complex materials. Energy Fuels. 1999;13:1-22.

13. Burnham AK, Dinh LN. A comparison of isoconversional and model-fitting approaches to kinetic parameter estimation and application predictions. J Therm Anal Calorim. 2007;89:479-90.

14. Friedman HL. Kinetics of thermal degradation of char-forming plastics from thermogravimetry. Application to a phenolic plastic. J Polym Sci Part C Polym Symp. 2010;6:183-95.

15. Grant DM, Pugmire RJ, Fletcher TH, Kerstein AR. Chemicalmodel of coal devolatilization using percolation lattice statistics. Energy Fuels. 1989;3:175-86.

16. Fletcher TH, Pond HR, Webster J, Wooters J, Baxter LL. Prediction of tar and light gas during pyrolysis of black liquor and biomass. Energy Fuels. 2012;26:3381-7.

17. Sheng C, Azevedo JLT. Modeling biomass devolatilization using the chemical percolation devolatilization model for the main components. Proc Combust Inst. 2002;29:407-14.

18. Lewis AD, Fletcher TH. Prediction of sawdust pyrolysis yields from a flat-flame burner using the CPD model. Energy Fuels. 2013;27:942-53.

19. Fletcher, Thomas H. Kerstein AR, Pugmire, Ronald J. Grant DM. A chemical percolation model for devolatilization: summary. J Chem Inf Model. 2013.

20. Lewis AD. Notes from Aaron Lewis for using CPD to predict biomass pyrolysis. 2015. http://www.et.byu.edu/ tom/devolatili zation/CPD\%20model.html.

21. Perry S. A global free-radical mechanism for nitrogen release during devolatilization based on coal chemical structure. Brigham Young Univ. 1999. 
22. Lewis AD, Fletcher TH. Predicting sawdust pyrolysis yields using the CPD code with a tar cracking model. Development. 2011;1-6.

23. Trendewicz A, Evans R, Dutta A, Sykes R, Carpenter D, Braun R. Evaluating the effect of potassium on cellulose pyrolysis reaction kinetics. Biomass Bioenerg. 2015;74:15-25.

24. Patwardhan PR, Satrio JA, Brown RC, Shanks BH. Influence of inorganic salts on the primary pyrolysis products of cellulose. Bioresour Technol. 2010;101:4646-55. https://doi.org/10.1016/j. biortech.2010.01.112.

25. Nowakowski DJ, Jones JM. Catalysis by potassium in the pyrolysis processes of biomass and basic biomass components. WREC. 2005.590-5.

26. Wang S, Liu Q, Liao Y, Luo Z, Cen K. A study on the mechanism research on cellulose pyrolysis under catalysis of metallic salts. Korean J Chem Eng. 2007;24:336-40.

27. Wang J, Zhang M, Chen M, Min F, Zhang S, Ren Z, et al. Catalytic effects of six inorganic compounds on pyrolysis of three kinds of biomass. Thermochim Acta. 2006;444:110-4.

28. Raveendran K, Ganesh A, Khilar KC. Influence of mineral matter on biomass pyrolysis characteristics. Fuel. 1995;74:1812-22.

29. Varhegyi G, Antal MJ, Szekely T, Till F, Jakab E, Varhegyi G. Simultaneous thermogravimetric-mass spectrometric studies of the thermal decomposition of biopolymers. 1. avicel cellulose in the presence and absence of catalysts. Energy and Fuels. 1988;2:267-72.

30. Liu D, Yu Y, Hayashi JI, Moghtaderi B, Wu H. Contribution of dehydration and depolymerization reactions during the fast pyrolysis of various salt-loaded celluloses at low temperatures. Fuel. 2014;136:62-8. https://doi.org/10.1016/j.fuel.2014.07.025.

31. Mayer ZA, Apfelbacher A, Hornung A. Effect of sample preparation on the thermal degradation of metal-added biomass. J Anal Appl Pyrolysis. 2012;94:170-6.

32. Liu D, Yu Y, Long $\mathrm{Y}, \mathrm{Wu} \mathrm{H}$. Effect of $\mathrm{MgCl} 2$ loading on the evolution of reaction intermediates during cellulose fast pyrolysis at 325 ??C. Proc Combust Inst. 2015;35:2381-8. https://doi.org/10. 1016/j.proci.2014.05.026

33. Yu Y, Liu D, Wu H. Formation and characteristics of reaction intermediates from the fast pyrolysis of $\mathrm{NaCl}$ - and $\mathrm{MgCl} 2$-loaded celluloses. Energy and Fuels [Internet]. 2014;28:245-53. https:// doi.org/10.1021/ef401483u.

34. Dufour A, Ouartassi B, Bounaceur R, Zoulalian A. Modelling intra-particle phenomena of biomass pyrolysis. Chem Eng Res Des. 2011;89:2136-46. https://doi.org/10.1016/j.cherd.2011.01. 005.

35. Fletcher TH, Pugmire RJ. Chemical percolation model for coal devolatilization. 1992.

36. Sonobe T, Worasuwannarak N. Kinetic analyses of biomass pyrolysis using the distributed activation energy model. Fuel. 2008;87:414-21.

37. Worasuwannarak N, Sonobe T, Tanthapanichakoon W. Pyrolysis behaviors of rice straw, rice husk, and corncob by TG-MS technique. J Anal Appl Pyrolysis. 2007;78:265-71.

38. Milosavljevic I, Suuberg EM. Cellulose thermal decomposition kinetics: global mass loss kinetics. Ind Eng Chem Res. 1995;34:1081-91.

39. Zhou X, Mayes HB, Broadbelt LJ, Nolte MW, Shanks BH. fast pyrolysis of glucose-based carbohydrates with added $\mathrm{NaCl}$ Part 1: experiments and development of a mehanistic model. AIChE J. 2016;62:766-77.

40. Zhou X, Mayes HB, Broadbelt LJ, Nolte MW, Shanks BH. Fast pyrolysis of gluocse-based carbohydrates with added $\mathrm{NaCl}$ part 2: validation and evaluation of the mechanistic model. AIChE J. 2016;62:778-91.

41. Essig M, Lowary T, Richards GN, Schenck E. Influences of "Neutral" salts on thermochemical conversion of cellulose and of sucrose. Res Thermochem Biomass Convers. p. 143-54.

42. Patwardhan P. Understanding the product distribution from biomass fast pyrolysis. Grad. Theses Diss. 2010. Available from: http://lib.dr.iastate.edu/etd/11767.

Publisher's Note Springer Nature remains neutral with regard to jurisdictional claims in published maps and institutional affiliations. 